\title{
EVALUASI PROGRAM EARLY WARNING ALERT AND RESPON SYSTEM (EWARS) DALAM PELAKSANAAN SURVEILANS KLB KOTA SALATIGA PROVINSI JAWA TENGAH
}

\author{
Nurvita Wikansari ${ }^{1}$, Dian Budi Santoso ${ }^{2}$, Dibyo Pramono ${ }^{2}$, Dyah W. Widarsih ${ }^{3}$ \\ ${ }^{1}$ STIKES AKBIDYO Yogyakarta, ${ }^{2}$ Universitas Gadjah Mada, ${ }^{3}$ Dinas Kesehatan Kota Salatiga \\ Email: dianbudisantoso@gmail.com ${ }^{1}$
}

\begin{abstract}
Outbreaks of disease can result in a large increase in morbidity and mortality, have an impact on tourism, economics and social, so there is a need for an Extraordinary Early Response and Response System (EWARS) (Early Warning and Response System). SKDR has been socialized and replicated gradually throughout Indonesia. Salatiga is one of the cities in Central Java Province and has 6 health centers that have been running the EWARS program in early detection of outbreaks but still occur every year. It is necessary to evaluate the EWARS Program at the Salatiga City Health Service.

Evaluation was carried out with a descriptive study of analysis, namely evaluating aspects of input, process, output and outcome by interviewing questionnaires to EWARS health center program administrators and Salatiga City Health Service.

The problem with input is that officers have multiple tasks $\geq 2(67 \%)$ and there are no adequate funds. In the process of targeting and planning (50\%) and coordination across sectors (33\%). At the output, the officer did not send the report on time and in the outcome of the detection of outbreaks as early as possible but there was no epidemiological bulletin to inform public health every week.

There are a number of things that need to be addressed in the EWARS program in Salatiga, namely human resources, facilities and infrastructure as well as planning and implementation. There needs to be equal employment, EWARS training for puskesmas officers and municipal health offices so that they can detect and analyze potentially outbreak diseases as early as possible. Keywords: program evaluation, EWARS, Salatiga
\end{abstract}

\begin{abstract}
ABSTRAK
KLB penyakit dapat mengakibatkan terjadinya peningkatan kesakitan dan kematian yang besar, berdampak pada pariwisata, ekonomi dan sosial, sehingga perlu adanya Sistem Kewaspadaan Dini dan Respon (SKDR) Kejadian Luar Biasa (KLB) atau EWARS (Early Warning and Respon System). SKDR telah disosialisasikan dan direplikasi secara bertahap di seluruh Indonesia. Salatiga merupakan salah satu Kota di Propinsi Jawa Tengah dan memiliki 6 puskesmas yang sudah menjalankan program EWARS dalam deteksi dini KLB namun tetap saja masih terjadi KLB setiap tahunnya. Perlu dilakukan evaluasi Program EWARS di Dinas Kesehatan Kota Salatiga.

Evaluasi dilakukan dengan kajian deskriptif analisis yaitu mengevaluasi aspek input, proses, output dan outcome dengan cara wawancara menggunakan kuisioner kepada petugas pengelola program EWARS puskesmas dan Dinas Kesehatan Kota Salatiga.

Masalah pada input yaitu petugas mempunyai tugas rangkap $\geq 2(67 \%)$ dan belum ada dana yang memadai. Pada proses yaitu pembuatan target dan perencanaan (50\%) serta koordinasi lintas sektor (33\%). Pada output, petugas tidak tepat waktu mengirim laporan dan pada outcome yaitu terdeteksinya KLB sedini mungkin namun belum terdapat buletin epidemiologi untuk menginformasikan kesehatan masyarakat setiap minggu.

Terdapat beberapa hal yang perlu dibenahi pada program EWARS di Kota Salatiga yaitu pada sumber daya manusia, sarana dan prasarana serta perencanaan dan pelaksanaannya. Perlu adanya pemerataan pekerjaan, pelatihan EWARS bagi petugas puskesmas dan dinas kesehatan kota sehingga dapat mendeteksi dan menganalisis penyakit berpotensi KLB sedini mungkin.

Kata kunci: evaluasi program, EWARS, Salatiga
\end{abstract}




\section{PENDAHULUAN}

Indonesia merupakan salah satu anggota dari organisasi Persatuan Bangsa - Bangsa (PBB) yang selalu mendukung kebijakan dari organisasi tersebut apabila tidak bertentangan dengan kebijakan nasional maupun internasionalnya. Indonesia telah meratifikasi IHR (Internasional Health Regulation) tahun 2005 maka harus mengikuti dan menjalankan aturan tersebut. WHO menyatakan bahwa IHR 2005 sesuai Bab II, Pasal 5, ayat 1 dan sebagai anggota dari World Health Organization (WHO), Indonesia harus mengembangkan, memperkuat, dan memelihara kemampuan untuk mendeteksi, menilai, dan melaporkan kejadian sedini mungkin (Kementerian Kesehatan RI, 2012).

Dalam era globalisasi ini mobilisasi manusia maupun barang sudah sangat tinggi dan sangat cepat. Tetapi kondisi ini juga dapat dilihat sebagai sebuah ancaman misalnya transmisi penyakit menular dari suatu Negara ke Negara lain. Salah satu contoh adalah Kejadian Luar Biasa (KLB) Polio di Indonesia tahun 2005 yang terjadi karena ada import virus polio dari Negara lain. Selain itu saat ini dunia telah mengalami perubahan iklim yang disebabkan oleh pemanasan global yang semakin cepat. Kondisi ini juga akan mempengaruhi pola dan jenis penyakit potensial wabah secara langsung maupun tidak langsung maupun penyakit new emerging seperti flu burung (Kementerian Kesehatan RI, 2012).

Kejadian luar biasa (KLB) penyakit menular, keracunan makanan, serta keracunan bahan berbahaya lainnya masih menjadi masalah kesehatan masyarakat karena dapat menyebabkan jatuhnya korban kesakitan dan kematian yang besar, menyerap anggaran biaya yang besar dalam upaya penanggulangannya, berdampak pada sektor ekonomi, pariwisata serta berpotensi menyebar luas lintas kabupaten/kota, propinsi bahkan internasional yang membutuhkan koordinasi dalam penanggulangannya (Kementerian Kesehatan RI, 2014).

Diare, campak dan demam berdarah dengue merupakan jenis penyakit yang sering menimbulkan KLB di Indonesia. Beberapa jenis KLB mengalami penurunan seperti diare, campak, dan malaria, tetapi beberapa jenis KLB penyakit lainnya justru semakin meningkat seperti demam berdarah, keracunan makanan dan bahan berbahaya lainnya serta munculnya KLB penyakit baru seperti SARS, HFMD, Hepatitis E dan lain - lain. Demikian juga beberapa penyakit yang sudah dianggap tidak menjadi masalah masyarakat timbul kembali seperti KLB difteri, chikungunya, leptospirosis dan kolera (Kementerian Kesehatan RI, 2014).

KLB penyakit dapat mengakibatkan terjadinya peningkatan kesakitan dan kematian yang besar, yang juga berdampak pada pariwisata, ekonomi dan sosial, sehingga membutuhkan perhatian dan penanganan oleh semua pihak terkait. Kejadian - kejadian KLB perlu dideteksi secara dini dan diikuti tindakan yang cepat dan tepat, perlu diidentifikasi adanya ancaman KLB beserta kondisi rentan yang memperbesar risiko terjadinya KLB agar dapat dilakukan peningkatan kewaspadaan dan kesiapsiagaan menghadapi kemungkinan KLB, dan oleh karena itu perlu adanya Sistem Kewaspadaan Dini dan Respon (SKDR) Kejadian Luar Biasa atau biasa disebut EWARS (Early Warning and Respon System). Karena terdapat 2 prinsip dalam sistem surveilance yang efektif yatiu memberikan peringatan dini perubahan insiden penyakit dan mendeteksi KBL lebih awal (Rolland, et al., 2006).

SKDR telah disosialisasikan dan direplikasi secara bertahap dan berjalan efektif di 24 provinsi, 377 kabupaten/kota serta 7529 puskesmas. Proses replikasi masih terus dilaksanakan sampai seluruh provinsi di Indonesia dapat mengimplementasikan sistem ini. Propinsi Jawa Tengah dilatih dan direplikasi pada tahun 2012 dengan jumlah kabupaten / kota sebanyak 35 yang terdiri dari 876 puskesmas. Salatiga merupakan salah satu Kota di Propinsi Jawa Tengah dan memiliki 6 puskesmas, yang terdiri dari Puskesmas Sidorejo Lor, Sidorejo Kidul, Mangusanri, Cebongan, Kalicacing, dan Tegalrejo. Penggunaan EWARS di Kota Salatiga belum optimal. Hal ini dilihat dari belum optimalnya pemanfaatan software EWARS di Dinas Kesehatan Kota Salatiga dan masih adanya keterlambatan pengumpulan informasi penyakit penyebab KLB ke Dinas Kesehatan Kota Salatiga.

\section{METODE PENELITIAN}

Evaluasi dilakukan dengan kajian deskriptif analisis yaitu mengevaluasi aspek input, proses, output dan outcome yang diperlukan 
untuk melihat ketepatan, kelengkapan, dan keteraturan pencatatan dan pelaporan, meliputi:

1. Input: SDM, dana, material, kebijakan, ketersediaan buku pedoman, dan penguasaan teknologi.

2. Proses: Perencanaan program, pelaksanaan dan monitoring evaluasi.

3. Output: dapat diketahuinya jumlah kasus baru setiap penyakit, total kunjungan, proporsi kesakitan, incidence rate, dan Alert KLB (secara teratur, KLB tidak besar dan berkepanjangan)

4. Outcome: Pengendalian KLB, sehingga KLB tidak menjadi masalah kesehatan masyarakat dan meminimalkan kesakitan dan kematian yang berhubungan dengan KLB

\section{Subyek Evaluasi}

Populasi pada evaluasi program EWARS adalah semua pelaksana Program EWARS di 6 Puskesmas dan 1 orang pengelola Program EWARS di Dinas Kesehatan Kota Salatiga. Dalam penelitian ini semua populasi dijadikan sampel.

\section{Alat Ukur}

Evaluasi program penanggulangan program EWARS dilakukan dengan kuesioner dan wawancara kepada pemegang program EWARS di puskesmas dan Dinas Kesehatan Kota Salatiga. Alat ukur dalam penelitian ini adalah dengan menggunakan kuesioner yang berisi pertanyaan tentang indikator input, proses, output dan outcome.

Pengumpulan Data

Data primer dikumpulkan dengan wawancara menggunakan kuesioner kepada petugas pengelola program EWARS puskesmas dan dinas kesehatan Kota Salatiga terhadap kegiatan input, proses, output dan outcome kegiatan EWARS. Sedangkan data sekunder diperoleh dari arsip laporan puskesmas dan program EWARS di seksi P3 Dinas Kesehatan Kota Salatiga

Cara Analisa Data

Data yang diperoleh selama kegiatan evaluasi yang meliputi input, proses, output dan outcome akan dianalisis dengan cara deskriptif untuk masing-masing variabel penelitian dengan cara membandingkan indikator yang telah dicapai dengan indikator pada pedoman EWARS.

\section{HASIL}

Input

Salah satu aspek yang dilakukan evaluasi terhadap program EWARS di Kota Salatiga adalah aspek input. Untuk mendukung program EWARS agar dapat berjalan dengan baik maka perlu dilengkapi dengan tenaga pelaksana program EWARS dengan jenis, jumlah dan kualitas yang memadai. Tenaga yang diperlukan tersebut adalah tenaga pengelola program yang dapat bertanggung jawab terhadap pencatatan dan pelaporan. Tenaga dalam pelaksanaan program EWARS berasal dari petugas Dinas Kesehatan Kota Salatiga dan petugas puskesmas Kota Salatiga.

Berikut hasil evaluasi aspek input yang berasal dari petugas Dinas Kesehatan Kota Salatiga :

Tabel 1. Aspek Input Program EWARS di Dinas Kesehatan Kota Salatiga Jawa Tengah

\begin{tabular}{|c|c|}
\hline \multicolumn{2}{|c|}{$\begin{array}{l}\text { Aspek Input Program EWARS } \\
\text { Dinas Kesehatan Kota Salatiga }\end{array}$} \\
\hline Jumlah tenaga & 1 orang \\
\hline Jenis Kelamin & Perempuan \\
\hline Umur (tahun) & 49 \\
\hline Tingkat Pendidikan & S2 Epidemiologi \\
\hline Lama bekerja di Program EWARS & 8 bulan \\
\hline Jumlah tugas rangkap & $\geq 2$ \\
\hline Pelatihan EWARS & Belum pernah \\
\hline Penguasaan Teknologi & Sedang \\
\hline Buku Pedoman & Ada \\
\hline Buku Algoritma Penyakit & Ada \\
\hline Formulir Pelaporan (W2 dan SMS) & Ada \\
\hline Komputer & Pribadi \\
\hline HP/Telepon genggam & Pribadi \\
\hline Sarana Transportasi & Pribadi \\
\hline Dana & Tidak Ada \\
\hline Perencanaan Program & Ya \\
\hline Pelaksanaan Program & $\begin{array}{ll}\text { Aktif } & \text { dengan } \\
\text { Supervisi } & \end{array}$ \\
\hline Format Laporan yang Dikirim & Lengkap \\
\hline Buletin Epidemiologi & Tidak \\
\hline Pertemuan Lintas Program & Ada \\
\hline Pertemuan Lintas Sektor & Ada \\
\hline $\begin{array}{l}\text { Feedback dari Dinas Kesehatan } \\
\text { Propinsi }\end{array}$ & Tidak Ada \\
\hline $\begin{array}{l}\text { Berdasarkan tabel di atas } \\
\text { bahwa pemegang program } \\
\text { memenuhi kualifikasi kare } \\
\text { program merupakan magiste } \\
\text { Namun, pemegang program } \\
\text { saat ini belum pernah men } \\
\text { mengenai EWARS. Adapaun } \\
\text { dengan pemegang program E }\end{array}$ & $\begin{array}{l}\text { lapat diketahui } \\
\text { WARS sudah } \\
\text { na pemegang } \\
\text { epidemiologi. } \\
\text { WARS sampai } \\
\text { ikuti pelatihan } \\
\text { hasil evaluasi } \\
\text { VARS di enam } \\
\text { ut: }\end{array}$ \\
\hline
\end{tabular}


Volume 02, No 01, Tahun 2019

ISSN: 2621-6612

Email: d3perinfokesunivet@gmail.com

Halaman: 9-17

\section{Tenaga}

Tabel 2. Karakteristik Pelaksana Program EWARS di Kota Salatiga

\begin{tabular}{llrr}
\hline No & Karakteristik & Jumlah & $\%$ \\
\hline 1 & Pendidikan & & \\
& SLTA & 1 & 17 \\
& Akademi & 5 & 83 \\
$2 \quad$ Umur & & \\
& $<45$ tahun & 3 & 50 \\
& $\geq 45$ tahun & 3 & 50 \\
3 & Tugas Rangkap & & \\
& 1 program & 1 & 17 \\
& 2 program & 2 & 33 \\
& 3 program & 1 & 17 \\
& 4 program & 0 & 0 \\
& Lebih dari 4 & & \\
& program & 2 & 33 \\
& Lama Menjabat & & \\
& $<1$ tahun & 2 & 33 \\
& 1 tahun & 1 & 17 \\
& $>1$ tahun & 3 & 50 \\
& Jumlah & 6 & 100 \\
\hline
\end{tabular}

Pada Tabel 2 dapat dilihat jika pendidikan pelaksana program EWARS di Puskesmas Kota Salatiga terbanyak memiliki pendidikan Akademi sebesar 83\%, sedangkan yang memiliki pendidikan SLTA sebesar $17 \%$. Pelaksana program EWARS di Kota Salatiga yang berumur $<45$ tahun sebesar $50 \%$ dan yang berumur $\geq 45$ tahun sebesar $50 \%$. Evaluasi kualitas tenaga diukur melalui pernah tidaknya mengikuti pelatihan tentang program EWARS. Di Kota Salatiga pelatihan program EWARS belum pernah ada sehingga para pemegang program di puskesmas belum pernah mengikuti pelatihan program EWARS. Selain dilihat dari pelatihan EWARS, kualitas tenaga juga dilihat dari adanya tugas rangkap yang dilakukan selain program EWARS. Hanya satu orang yang memegang 1 program saja, sedangkan yang lain masih memegang lebih dari satu program. Bahkan ada 2 orang yang memegang lebih dari 4 program. Tugas rangkap yang dilakukan oleh petugas pengelola program EWARS antara lain sebagai tenaga P2 diare, P2 ISPA pneumonia, P2 DBD, dan P2 Leptospirosis.

Sebanyak 2 orang $(33 \%)$ petugas pengelola program EWARS di Kota Salatiga lama menjabat kurang dari satu tahun, sedangkan yang menjabat lebih dari satu tahun ada 3 orang $(50 \%)$.

\section{Sarana dan Prasarana}

Untuk kelancaran pelaksanaan program EWARS yang sesuai dengan standar petunjuk teknis secara nasional, maka semua puskesmas atau pemegang program EWARS di Kota Salatiga diberi sarana dan prasarana seperti tampak pada Tabel 3.

Tabel 3. Ketersedian Sarana dan Prasarana

EWARS Pada Puskesmas di Kota Salatiga

\begin{tabular}{llrr}
\hline No & Sarana dan Prasarana & Jumlah & $\%$ \\
\hline 1 & Buku Pedoman & & \\
& Ada & 4 & 67 \\
& Tidak & 2 & 33 \\
2 & Jenis Formulir & & \\
& $\begin{array}{l}\text { Form Algoritma } \\
\text { Penyakit } \quad \text { Pencatatan }\end{array}$ & 6 & 100 \\
& Form & & \\
& EWARS & 4 & $67 \%$ \\
3 & Jenis Alat & & \\
& Komputer & 6 & 100 \\
& Kendaraan Bermotor & 2 & $33 \%$ \\
& HP & 0 & 0 \\
\hline
\end{tabular}

Pada Tabel 3 dapat dilihat sebanyak 4 (67\%) puskesmas telah memiliki buku pedoman EWARS namun masih ada $2(33 \%)$ puskesmas yang tidak memiliki buku pedoman EWARS, yaitu Puskesmas Cebongan dan Puskesmas Tegalrejo. Sebanyak 6 puskesmas telah memiliki ketersediaan formulir algoritma penyakit dalam EWARS (100\%). Namun, hanya 4 puskesmas yang memiliki buku pencatatan EWARS (67\%). Dari sisi alat pengolah data, setiap puskesmas terdapat komputer yang bisa dimanfaatkan untuk program EWARS. Namun pemanfaatan komputer ini tidak maksimal dikarenakan semua program menggunakan satu komputer tersebut sehingga pemakaiannya bergantian dengan program lain. Selain itu tidak semua pemegang program pandai dalam penggunaan komputer terutama dalam pemakaian aplikasi EWARS. Hal ini juga dikarenakan belum pernah diadakan pelatihan penggunaan aplikasi EWARS di setiap puskesmas, bahkan di Dinas Kesehatan Kota pelatihan bukan diikuti oleh pemegang program EWARS saat ini. Untuk alat transportasi hanya $2(33 \%)$ puskesmas yang sudah menggunakan alat transportasi untuk melaksanakan program EWARS jika terjadi peringatan yang memungkinkan untuk turun ke lapangan. Sedangkan alat komunikasi 
Volume 02, No 01, Tahun 2019

ISSN: 2621-6612

Email: d3perinfokesunivet@gmail.com

Halaman: 9-17

seperti HP, pemegang program tidak disediakan alat komunikasi khusus untuk melaksankan program EWARS ini. Alat komunikasi menggunakan telepon genggam pribadi untuk mengirim sms setiap minggu.

\section{Ketersediaan Dana}

Salah satu input yang penting dalam program EWARS adalah dana. Kegiatan program EWARS di Kota Salatiga di puskesmas belum mempunyai anggaran khusus yang di danai oleh APBD Pemerintah Kota Salatiga. Berdasarkan hasil wawancara dengan pengelola program EWARS diketahui bahwa dana yang ada berasal dari dinas kesehatan Kota yang berasal dari dinas kesehatan propinsi dimana hanya sebesar $\mathrm{Rp} 100.000,00$ yang diberikan hanya setahun sekali sebagai pengganti pulsa sms. Sedangkan khusus dari puskesmas belum ada karena dianggap bukan merupakan prioritas di puskesmas - puskesmas tersebut. puskesmas baru dilakukan oleh 3 puskesmas (50\%), sedangkan untuk perencanaan kegiatan EWARS, rencana kebutuhan, dan rencana pelaksanaan monitoring dan evaluasi hanya dilaksanakan oleh 1 puskesmas (17\%) yaitu puskesmas Sidorejo Lor.

Proses perencanaan dalam hal ini meliputi tahapan: analisis situasi, identifikasi dan penetapan masalah prioritas, menetapkan tujuan untuk mengatasi masalah, menetapkan alternatif pemecahan masalah, menyusun rencana kegiatan dan penganggaran (POA), menyusun rencana pemantauan dan evaluasi.

Selain pemegang program di puskesmas, pemegang program EWARS di Dinas Kesehatan Kota Salatiga juga membuat perencanaan mengenai target yang akan dicapai, daftar kebutuhan bahan dan peralatan, serta rencana kapan akan diadakannya monitoring dan evaluasi tingkat puskesmas

\section{Proses}

Pada aspek proses, dilihat perencanaan, pelaksanaan, serta monitoring dan evaluasi dari program EWARS yang dilaksanakan oleh pelaksana program EWARS dan pemegang program EWARS. Dari tabel 4 dapat dilihat jika perencanaan target EWARS tingkat

Tabel 4. Proses Program EWARS pada Puskesmas di Kota Salatiga

\begin{tabular}{llrr}
\hline No & Input & Jumlah & $\%$ \\
\hline 1 & Perencanaan & & \\
& Rencana Target Program EWARS & 3 & 50 \\
& Dokumen Tertulis Perencanaan EWARS Puskesmas & 1 & 17 \\
& Dokumen Tertulis Kebutuhan EWARS Puskesmas & 1 & 17 \\
& Rencana Kegiatan Monitoring dan Evaluasi & 1 & 17 \\
2 & & \\
Pelaksanaan & 4 & 67 \\
Deteksi KLB aktif & 2 & 33 \\
Deteksi KLB pasif & 5 & 83 \\
Pertemuan Lintas Program & 2 & 33 \\
Pertemuan Lintas Sektor & 3 & 50 \\
Pembinaan kader & 6 & 100 \\
Pembuatan PWS & 6 & 100 \\
Pencatatan dan Pelaporan & 2 & 33 \\
Indentifikasi Masalah Program dan Rencana Tindak Lanjut & & \\
Monitoring dan Evalausi & 1 & 17 \\
Monev Tingkat Puskesmas & 6 & 100 \\
Monev Tingkat Kota & 6 & 100 \\
\hline Supervisi Tingkat Kota
\end{tabular}


Pelaksanaan EWARS tingkat puskesmas dilakukan mulai dari deteksi yang aktif sudah dilakukan lebih dari setengah puskesmas di Kota Salatiga, pertemuan lintas program yang dilakukan 5 puskesmas, pembuatan PWS dan pencatatan serta pelaporan yang dilakukan oleh keenam puskesmas. Tetapi dalam pertemuan lintas sektor dan identifikasi masalah program serta rencana tindak lanjutnya hanya dilakukan oleh 2 puskesmas saja. Sedangkan pembinaan kader hanya dilakukan oleh 3 puskesmas.

Sementara Program EWARS di Kota Salatiga dikoordinasikan di bawah Seksi Pencegahan dan Penanggulangan Penyakit Bidang Pemberantasan Penyakit dan Penyehatan Lingkungan Dinas Kesehatan Kota Salatiga. Pengelola program EWARS dilakukan oleh seorang pemegang program yang berpendidikan S2 Epidemiologi.

Monitoring dan evaluasi dilihat dengan kegiatan supervisi, dimaksudkan untuk meningkatkan kinerja petugas dengan mempertahankan kompetensi dan motivasi petugas yang disupervisi. Supervisi merupakan unsur penting dalam bimbingan dan pengendalian suatu program. Pelaksanaan program EWARS di Kota Salatiga dilakukan oleh kepala puskesmas dan pemegang program dari Dinas Kesehatan Kota Salatiga. Tujuan supervisi untuk mengetahui jalannya pelaksanaan program EWARS. Monitoring dan evaluasi EWARS tingkat puskesmas hanya dilakukan oleh 1 puskesmas (17\%), Namun supervisi tingkat Kota dilakukan oleh petugas dinas kesehatan kota ke semua puskesmaas $(100 \%)$ setiap setahun sekali dan berkelanjutan. Adapun materi dari supervisi tersebut adalah melihat administrasi dari petugas program EWARS yaitu bentuk pencatatan dan pelaporannya, hasil kegiatan program EWARS selama tahun berjalan dan diskusi tentang rencana intervensi serta kendala-kendala yang dihadapi untuk dicarikan solusi secara bersama-sama

\section{Output}

Output program EWARS di Kota Salatiga dapat dilihat dengan menghitung jumlah pengiriman laporan penyakit dalam EWARS yang dapat menimbulkan KLB pada masing masing puskesmas. Pada tahun 2014, semua puskesmas telah mengirim short message service (sms) ke pemegang program Dinas Kesehatan Kota Salatiga sebanyak 52 kali karena dalam satu tahun di tahun 2014 terdapat
52 minggu. Namun pengiriman laporan tidak selalu tepat waktu di hari sabtu setiap minggunya. Sedangkan kelengkapan dari pelaporan sudah baik karena formulir sudah disepakati oleh pihak puskesmas dan pihak dinas kesehatan kota. Para pemegang program di puskesmas juga sudah menjalankan dan mengirimkan laporan sesuai dengan pedoman algoritma penyakit.

\section{Outcome}

Outcome program EWARS di Kota Salatiga dapat dilihat dengan menghitung jumlah kejadian KLB pada masing - masing puskesmas seperti pada Tabel 5.

Tabel 5. Kejadian KLB di Kota Salatiga Tahun $2012-2014$

\begin{tabular}{llrrr}
\hline \multirow{2}{*}{ No } & \multirow{2}{*}{ Puskesmas } & \multicolumn{3}{c}{ KLB } \\
\cline { 3 - 5 } & & 2012 & 2013 & 2014 \\
\hline 1 & Cebongan & - & 1 & - \\
2 & Kalicacing & 1 & 1 & 2 \\
3 & Sidorejo Lor & - & - & - \\
4 & Sidorejo Kidul & - & - & - \\
5 & Tegalrejo & - & 2 & - \\
6 & Mangunsari & 1 & - & - \\
& Total & 2 & 4 & 2 \\
\hline
\end{tabular}

Dari Tabel 5 tersebut dapat diketahui bahwa pada tahun 2012 terjadi 2 KLB yaitu di puskesmas Kalicacing dan Puskesmas Mangunsari, tahun 2013 terjadi 4 KLB di puskesmas 1 Cebongan, 1 Kalicacing, dan 2 Tegalrejo, sedangkan tahun 2014 hanya 2 KLB yaitu di puskesmas Kalicacing. KLB yang terjadi adalah KLB DBD, Chikungunya, Diare, dan Keracunan Makanan.

\section{PEMBAHASAN}

Program EWARS di Kota Salatiga telah dilaksanakan dengan seoptimal mungkin, namun masih terdapat hal-hal yang perlu untuk dipertimbangkan dalam rangka perbaikan.

Input

Berdasarkan hasil evaluasi pada aspek input, jumlah pelaksana program EWARS di Kota Salatiga telah mencukupi. Dimana di setiap puskesmas sudah memiliki tenaga pelaksana program EWARS. Tetapi yang menjadi masalah bahwa semua petugas program EWARS belum mendapatkan pelatihan sama sekali. Implementasi EWARS seharusnya dibagi ke dalam 2 periode yaitu 
periode pelatihan dan periode validasi untuk memastikan sistem dapat terimplementasi dengan baik (Hoot \& Aronsky, 2006).

Selain tidak adanya pelatihan, tugas rengkap juga menjadi kendala. Bahkan dari 6 puskesmas yang di evaluasi ada 2 petugas puskesmas yang mempunyai tugas rangkap lebih dari 4 program, hal ini sangat berpengaruh terhadap kualitas kerja serta menghambat pencapaian program EWARS di Kota Salatiga. Walaupun belum pernah diadakan pelatihan khusus EWARS untuk pemegang program, namun sosialisasi mengenai pelaksanaan EWARS pernah dilakukan.

Tingkat pendidikan tenaga pelaksana program EWARS Puskesmas di Kota Salatiga tertinggi adalah akademi (D3) sebanyak 5 orang (83\%) sedangkan yang tamat SLTA hanya 1 orang $(17 \%)$. Hal ini kurang ideal karena petugas program EWARS di puskesmas Kota Salatiga seharusnya minimal D3 karena diharapkan akan mudah dalam melakukan deteksi dini terhadap penyakit yang dapat menimbulkan wabah.

Ketersediaan formulir di puskesmas mencapai $100 \%$. Berarti semua puskesmas di Kota Salatiga sudah tidak kekurangan dalam ketersediaan formulir algoritma. Hal ini akan memperlancar kegiatan petugas program EWARS dalam melaksanakan EWARS. Namun belum semua puskesmas memiliki buku catatan khusus EWARS. Bahkan buku catatan dicampur dengan catatan program lain. Hal ini menyulitkan petugas dalam monitoring penyakit dalam EWARS sehingga sulit juga dalam menganalisa penyakit - penyakit yang dapat menimbulkan wabah dalam EWARS. Untuk buku-buku tentang EWARS dan algoritma EWARS sebetulnya dari Dinas Kesehatan sudah mendistribusikan ke semua puskesmas yang ada di wilayah Kota Salatiga, tetapi dari hasil evaluasi di 6 puskesmas hanya 4 puskesmas yang memiliki buku pedoman, mungkin hal ini terjadi pada saat pergantian petugas program EWARS maupun dipinjam oleh petugas lain tetapi belum dikembalikan. Seharusnya buku-buku tersebut selalu ada di tangan petugas pemegang program EWARS sehingga apabila petugas mengalami kendala dalam pelaksanaan program bisa melihat dan membaca buku-buku tersebut.

Belum ada dana khusus dari puskesmas untuk program EWARS. Belum ada dana khusus ini dimungkinkan karena program EWARS tidak menjadi prioritas program di puskesmas. Perlu peningkatan usulan dana APBD Kabupaten atau dicarikan dana lain untuk membantu pelaksanaan program EWARS di puskesmas agar petugas juga semangat dalam pelaksanaan program EWARS. Bagi negara berkembang seperti Indonesia, sebaiknya juga terdapat dana dari pihak luar (Ali, et al., 2018).

Ketersediaan alat pengolah data juga belum optimal. Mengingat puskesmas sebagai ujung tombak surveilans maka selayaknyalah jika setiap pelaksana program di puskesmas memiliki alat untuk mengolah data sehingga dapat meningkatkan sistem surveilans dan diharapkan meningkatkan sistem kewaspadaan dini di wilayah kerjanya.

Sarana Transportasi yang ada masih belum mencukupi kebutuhan. Jika terjadi KLB, pemegang program EWARS menuntut mobilisasi yang tinggi agar pelaksanaan kegiatan lebih optimal, dan hal ini membutuhkan sarana transportasi untuk menjangkau wilayah yang jauh. Hanya 2 puskesmas yang pemegang programnya menggunakan alat transportasi dari puskesmas.

\section{Proses}

Belum semua puskesmas melaksanakan perencanaan EWARS dengan baik. Hanya 3 puskesmas yang menetapkan target EWARS, sedangkan untuk perencanaan target, kegiatan baru, rencana kebutuhan, dan rencana pelaksanaan monitoring dan evaluasi hanya dilaksanakan oleh 1 puskesmas (17\%) yaitu puskesmas Sidorejo Lor. Proses perencanaan dalam hal ini meliputi tahapan: analisis situasi, identifikasi dan penetapan masalah prioritas, menetapkan tujuan untuk mengatasi masalah, menetapkan alternatif pemecahan masalah, menyusun rencana kegiatan dan penganggaran (POA), menyusun rencana pemantauan dan evaluasi. Hal ini akan menyulitkan pemegang program dalam menentukan output dan outcome jika tidak ada perencanaan diawal program. Dibutuhkan sebuah perencanaan yang komprehensif dalam sebuah program kesehatan (Fisher, et. al., 2016). Perecanaan sebaiknya diawali dari puskesmas dapat dikoordinasikan pada tenaga kesehatan lain yang berhubungan dengan program EWARS, misalnya dengan dokter, tenaga gizi, sanitarian dan petugas pemegang program lainnya.

Pelaksanaan EWARS tingkat puskesmas dilakukan puskesmas mulai dari deteksi dini KLB, pertemuan tingkat puskesmas, pertemuan lintas program dan lintas sektoral, pemantauan 
wilayah setempat, pencatatan dan pelaporan, identifikasi dan tindak lanjut masalah program EWARS. Tetapi tidak semua puskesmas melaksanakan seluruh tahapan tersebut. Hanya dalam pembuatan Pemantauan Wilayah Setempat (PWS) dan pelaporan saja yang sudah dilaksanakan oleh keenam puskesmas. Pelaporan keenam puskesmas juga tidak tepat waktu hal ini dikarenakan perekapan data yang terlambat karena komputer yang digunakan secara bergantian dengan program lain, sibuknya pemegang program karena tidak hanya memegang program EWARS saja, saat akan mengirim tidak ada pulsa yang akan digunakan.

Monitoring dan Evaluasi program EWARS dilakukan oleh kepala puskesmas dan pemegang program dari Dinas Kesehatan Kota Salatiga dengan melakukan kegiatan supervisi. Kegiatan supervisi dimaksudkan untuk meningkatkan kinerja petugas dengan mempertahankan kompetensi dan motivasi petugas yang disupervisi. Supervisi merupakan unsur penting dalam bimbingan dan pengendalian suatu program. Namun supervisi program EWARS hanya dilakukan setahun sekali atau saat KLB terjadi saja. Sebaiknya setiap bulan dilakukan supervisi agar pencatatan dan pelaporan tepat waktu dan bisa dilakukan analisis dan monitoring penyakit penyakit yang dapat terdapat dalam EWARS. Salah satu masalah dalam pelaksanaan program kesehatan adalah kurangnya supervisi yang menyebabkan program tersebut todak terkontrol dengan baik (Ndima, 2016).

\section{Output}

Output program EWARS di Kota Salatiga yaitu dengan melihat bahwa semua petugas puskesmas mengirimkan laporan berupa short message service (SMS) ke petugas dinas kesehatan setiap minggunya yaitu mengirimkan jumlah kasus penyakit dalam EWARS sehingga dinas kesehatan dapat memantau jumlah kasus penyakit yang dapat menimbulkan wabah dengan melihat peringatan dini dari sistem EWARS. Laporan yang dikirimkan masih belum tepat waktu karena banyak yang memiliki hambatan atau kendala seperti pulsa habis, tugas rangkap, komputer untuk bersama, dan lain - lain. Formulir yang sudah terisi maka dikirimkan ke dinas kesehatan kota dan biasanya lengkap sesuai dengan format laporan yang sudah disepakati. Laporan sering tidak tepat waktu untuk dikirimkan namun laporan selalu konsistensi atau terus menerus dikirimkan untuk mengetahui penyakit yang dapat menyebabkan wabah setiap minggunya. Penggunaan sistem berbasis elektronik seharusnya meningkatkan kualitas pelaporan dari sebuah program kesehatan (Birkhead, et. al., 2015).

\section{Outcome}

Outcome program EWARS dapat dilihat dengan menghitung jumlah KLB yang terjadi setiap tahunnya. Hasil aspek outcome dapat dilihat dari tahun 2012-2014 dimana masih adanya KLB di Kota Salatiga setiap tahunnya. Hal ini menggambarkan jika penggunaan EWARS kurang optimal. Hasil dari program ini, Dinas Kesehatan Kota Salatiga juga belum membuat bulletin epidemiologi yang dapat dibaca petugas kesehatan agar dapat menambah informasi mengenai pemyakit yang berkembang di masyarakat. Pelaporan biasanya terkait dengan pengolahan dan analisa data yang seharusnya dibuat oleh petugas pemegang program di puskesmas atau di dinas kesehatan namun saat ini belum ada pengolahan dan analisa data dari program EWARS ini.

\section{KESIMPULAN}

Berdasarkan evaluasi program EWARS di Kota Salatiga tahun 2014, dapat disimpulkan bahwa:

1. Pemegang program EWARS belum pernah mengikuti pelatihan Dinas Kesehatan Propinsi Jawa Tengah maupun Dinas Kesehatan Kota Salatiga serta petugas masih banyak yang memegang tugas rangkap di puskesmas.

2. Pendanaan, alat bantu pengolahan data dan sarana transportasi belum memadai untuk memenuhi kebutuhan dalam melaksanakan kegiatan EWARS. Buku pedoman dan algoritma penyakit tersedia di beberapa puskesmas walaupun tidak semuanya ada.

3. Pelaksanaan EWARS tingkat puskesmas sudah berjalan dengan baik yaitu dengan selalu mengirimkan laporan berupa SMS ke dinas kesehatan walaupun tidak tepat waktu.

4. Monitoring dan evaluasi EWARS tingkat puskesmas hanya dilakukan di satu puskesmas saja, namun monitoring tingkat kota dilakukan di semua 6 puskesmas (100\%), sementara supervisi dilakukan oleh petugas Dinas Kesehatan Kota Salatiga ke puskesmas setiap setahun sekali secara berkala dan berkelanjutan. 
Volume 02, No 01, Tahun 2019

ISSN: 2621-6612

Email:_d3perinfokesunivet@gmail.com

Halaman: 9-17

\section{SARAN}

1. Perlu dilaksanakan pelatihan EWARS bagi pemegang program EWARS di puskesmas.

2. Perlu pengadaan alat olah data (komputer), sarana transportasi, dan buku pedoman yang lebih merata ke semua puskesmas.

3. Perlu dilakukan monitoring dan evaluasi program EVARS di setiap puskesmas.

\section{DAFTAR PUSTAKA}

Ali, H., Kiama, C., Muthoni, L., Waruru, A., Young, P. W., Zielinski-Gutierrez, E., Waruiru, W., Harklerode, R., Kim, A. A., Swaminathan, M., De Cock, K. M., Wamicwe, J. (2018). Evaluation of an HIV-Related Mortuary Surveillance System - Nairobi, Kenya, Two Sites, 2015. MMWR Surveill Summaries, 67(14).

Birkhead, G., Klompas, M., Shah, N. R. (2015). Uses of Electronic Health Records for Public Health Surveillance to Advance Public Health. Annual Review of Public Health, 36, 345-359.

Fisher, H. H., Hoyte, T., Purcell, D. W. (2016). Health Department HIV Prevention Programs That Support the National HIV/AIDS Strategy: The Enhanced Comprehensive HIV Prevention Planning Project, 2010-2013. Public Health Reports, 131, 185-194.

Hoot, N., Aronsky, D. (2006). An Early Warning System for Overcrowding in the Emergency Department. AMIA Annual Symposium Proceeding.

Kementerian Kesehatan RI. (2012). Algoritma Diagnosis Penyakit dan Respon serta Format Penyelidikan Epidemiologi. Jakarta: Kementerian Kesehatan Republik Indonesia.

Kementerian Kesehatan RI. (2012). Pedoman Sistem Kewaspadaan Dini dan Respon. Jakarta: Kementerian Kesehatan Republik Indonesia.

Kementerian Kesehatan RI. (2014). Data Surveilans dan KLB 2013. Jakarta:
Kementerian Kesehatan Republik

Indonesia.

Kementerian Kesehatan RI. (2014). Peraturan Menteri Kesehatan Republik Indonesia Nomor 45 Tahun 2014 tentang Penyelenggaraan Surveilans Kesehatan. Jakarta: Kementerian Kesehatan Republik Indonesia.

Ndima, S. D., Sidat, M., Give, C., Ormel, H., Kok, M. C., Taegtmeyer, M. (2015). Supervision of community health workers in Mozambique: a qualitative study of factors influencing motivation and programme implementation. Human Resources for Health, 13.

Rolland, E., Moore, K. M., Robinson, V. A., McGuinness, D. (2006). Using Ontario's "Telehealth" health telephone helpline as an early-warning system: a study protocol. BMC Health Services Research, 6(10). 